\title{
Tribological Properties of Metal V-Belt Type CVT Lubricant
}

\author{
Keiichi Narita \\ Lubricants Research Laboratory, Idemitsu Kosan Co., Ltd., 24-4 Anesakikaigan, Chiba, Ichihara-shi 299-0107, Japan \\ Correspondence should be addressed to Keiichi Narita, keiichi.narita@si.idemitsu.co.jp
}

Received 26 July 2012; Accepted 11 September 2012

Academic Editor: Philippe Velex

Copyright () 2012 Keiichi Narita. This is an open access article distributed under the Creative Commons Attribution License, which permits unrestricted use, distribution, and reproduction in any medium, provided the original work is properly cited.

\begin{abstract}
The priority for lubricant performance for metal V-belt-type CVT (B-CVTFs) should be the improvement of transmittable torque capacity between the belt and pulley plus excellent antishudder properties for lockup clutch used in B-CVTs. This study intends to investigate the effect of lubricant additives for improving these performances of B-CVTs. In addition, surface analysis techniques were utilized to gain a novel insight into the chemical composites and morphology of the tribofilms. As a result, it is vital for greater torque capacity to give higher boundary friction coefficient between the metal contacting interfaces, and the process of boundary lubricant film formation derived from antiwear additives used in B-CVTFs strongly impacts on the torque capacity. Moreover, it is found that a sort of lubricant formulation gave an excellent antishudder performance for wet clutch with keeping higher friction coefficient between the metals, which would result in improving the performance of B-CVTs.
\end{abstract}

\section{Introduction}

There are two types of transmissions used in automobiles: automatic and manual. A market share of automatic transmissions referred to as ATs has been over $97 \%$ of all transmissions installed in automobiles in Japan [1]. In particular, there is an increasing number of passenger cars that feature continuously variable transmissions (CVTs) because CVTs achieve better fuel economy. Among CVTs, the number of cars with metal push belt-type CVTs (B-CVTs) has steadily increased each year and is currently applied to cars with an engine displacement of more than 3 liters. B-CVT consists of a steel belt made up of about 400 segments and laminated rings, as shown in Figure 1. Power is transmitted by the frictional force generated between the belt and pulley. In order to improve transmission efficiency and spread the application to CVTs to larger cars, belt CVT lubricant oils (B-CVTFs) must produce a higher transmission torque capacity between the belt and pulley. Therefore, the priority for the performance of CVT fluids should be focused on the improvement of torque capacity.

There are some reports regarding the effects of lubricants on the performance of a CVT [2-4]. For example, the films generated by Zinc dithiophosphate (ZnDTP) additives in the contact regions are known to contribute to achieve a higher metal-metal friction coefficient [2]. The information gained regarding the tribofilms of $\mathrm{ZnDTP}$ is helpful when considering the additive reaction from lubricants. ZnDTP tribofilms do not develop in rolling contact or if the hydrodynamic film thickness is significantly greater than the surface roughness [5]. Organic compounds around 100-nm thick were identified as the uppermost layer of the film, with $\mathrm{P}_{2} \mathrm{O}_{5}, \mathrm{ZnS}, \mathrm{FeO}, \mathrm{FeS}$, and $\mathrm{H}_{2} \mathrm{O}$ detected beneath this organic layer [6]. These latter compounds are considered to comprise a glassy phosphate, which is closely associated with antiwear performance. It has also been reported that ZnDTP films may form a pad-like structure consisting of glassy phosphate with an outer layer of $\mathrm{Zn}$ polyphosphate of $10 \mathrm{~nm}$ thickness $[7,8]$. Friction-velocity characteristics of oils containing ZnDTP and analysis of their tribofilms were reported [9].

In addition to giving higher torque capacity in the belt system, B-CVTFs must be compatible with lockup clutch fitted in the torque converter. Thus, CVTFs should also give a slightly lower friction coefficient at the engagement of lockup clutch usually made of cellulose fibers, which is generally called antishudder characteristics for wet clutch system. For the improvement of antishudder, friction modifiers are needed to be added into B-CVTFs. This trend is not desirable for the friction coefficient between the metal contacting pairs such as the belt and pulley in the CVT and has let lubricant additive formulation to be complicated for CVT applications. This study intends to investigate the effect of 


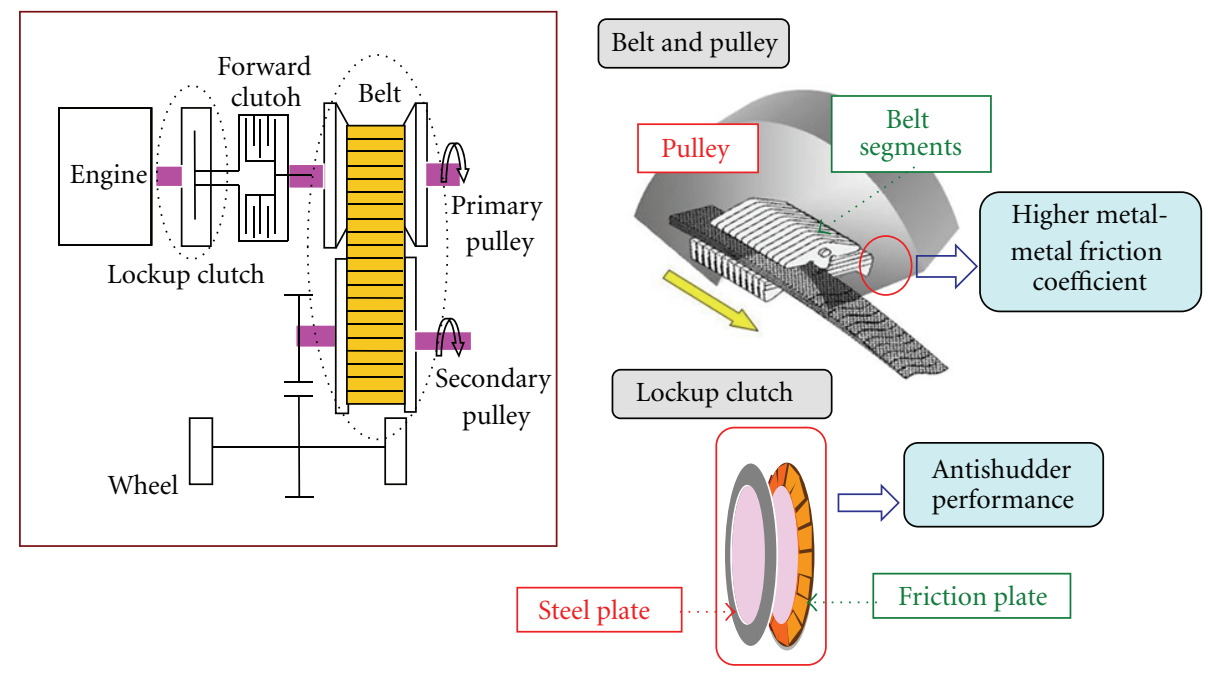

Figure 1: Constitution of Belt CVT unit.

lubricant additives such as antiwear additive, detergent, and friction modifier (FM) for improving these performances of B-CVTFs. Furthermore, atomic force microscopy (AFM) and X-ray photoelectron spectroscopy (XPS) were used for considering the nature of the tribofilms derived from candidate additives. The practical performance of candidate oil was evaluated by using actual belt CVT tester.

\section{Experimental Methods}

2.1. Block on Ring Tribometer (LFW-1). The friction characteristics between the metals were evaluated using a block on ring-type tribometer (Falex LFW-1) by varying the sliding speed from 1.0 to $0.025 \mathrm{~m} / \mathrm{s}$ with a constant load of $1112 \mathrm{~N}$ $\left(P_{\max } 0.6 \mathrm{GPa}\right)$ and a constant oil temperature $\left(110^{\circ} \mathrm{C}\right)$, as shown in Figure 2. The test procedure used in this study is based upon JASO M358 high-load condition [10] for assessing the torque capacity in a CVT between candidate oil and reference oil.

2.2. Belt CVT Bench Test. Parameters influencing the transmittable torque capacity were evaluated using a CVT bench tester, as shown in Figure 3. This test rig was designed to evaluate the transmission performance which is caused by the friction characteristics in essential CVT parts of the belt and pulley; it is not a whole gearbox. The belt assembly and pulley were taken out of a commercial CVT unit and set in the belt box. The bearings supporting the pulley shafts are hold in the pillow blocks. An AC motor drives the primary pulley and the drive torque is transmitted to the secondary pulley through the belt. The output from the secondary pulley is absorbed by a dynamometer. Speed and torque transducers were connected to the drive and output shafts.

There are slip phenomena due to relative motion between the belt and pulley. In particular, a large slip between the belt and pulley could cause a significant damage to the belt side and pulley sheave surface because the contacting pressure between the belt and pulley is estimated at more than $100 \mathrm{MPa}$ [11]. The relative slip between the belt and pulley

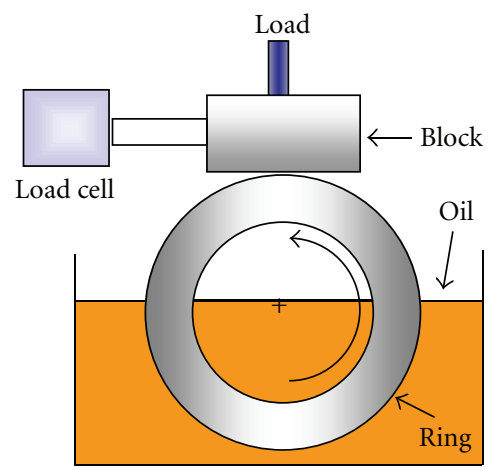

Test condition (JASO M358 high load)

\begin{tabular}{|l|l|l|}
\hline \multirow{2}{*}{ Test specimens } & Ring & S10 \\
\cline { 2 - 3 } & Block & H60 \\
\hline Load, N & 1112 \\
\hline Pressure $(P \max )(\mathrm{GPa})$ & 0.6 \\
\hline Speed $(\mathrm{m} / \mathrm{s})$ & $0.025-1$ \\
\hline Oil temperature $\left({ }^{\circ} \mathrm{C}\right)$ & 110 \\
\hline
\end{tabular}

FIGURE 2: Schematic of block on ring tribometer.

will be more significant with the increase of input torque, which is defined as the slip ratio between the belt and pulley, SR as shown in [12]:

$$
\mathrm{SR}=\frac{\left(I_{L}-I_{N}\right)}{I_{N}} \times 100(\%),
$$

where $I_{L}$ is the speed ratio at a loaded condition and $I_{N}$ is the specific value at a no load.

Speed ratio is defined as

$$
I=\frac{N_{p}}{N_{s}} .
$$




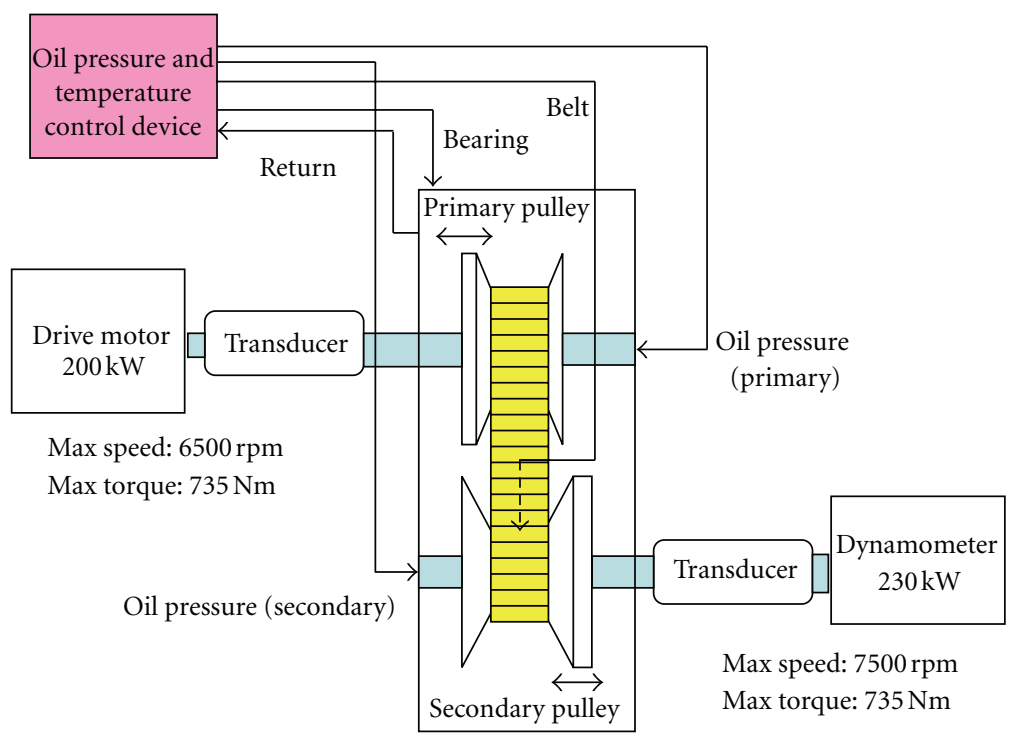

Figure 3: Schematic of Belt CVT bench tester.

$N_{p}$ and $N_{s}$ are the rotational speed on the primary and the secondary pulleys, respectively.

Under lower drive torque conditions, some of the power in the belt are passed by the bands tension not by compression in the segments, and there is a very small increase in the slip ratio. The slip ratio suddenly rises at approximately quarter load, which corresponds to the transition point, at which the compression side and the slack side change sides. When the drive torque reaches the slip limit torque, a macroslip occurs and no more torque can be transmitted. This macroslip is known to occur on the condition when the slip ratio reaches 4-6 percent [12].

Torque capacity tests were conducted by holding the primary pulley speed stable at $14 \mathrm{~m} / \mathrm{s}$ and the low speed ratio of 2.3. The drive torque was raised step by step at a rate of $5 \mathrm{Nm}$ every minute until a remarkable increase in the slip ratio was detected. Torque capacity of test oil was then defined as the drive torque at the moment when the slip ratio reached 3 percent so that the belt system would not be significantly damaged.

2.3. Low Velocity Friction Apparatus (LVFA). Low Velocity Friction Apparatus (LVFA) based upon JASO M349 [13] was used for antishudder properties for lockup clutch composed of friction plate and steel plate. This test method as shown in Figure 4 is widely used for evaluating friction behavior for the wet clutch system in the transmissions. Running-in operation for 30 minutes shall be conducted in accordance with the conditions at contacting pressure of $1.0 \mathrm{MPa}$, $0.6 \mathrm{~m} / \mathrm{s}$ sliding speed, and $80^{\circ} \mathrm{C}$ oil temperature. Upon completion of running-in operations, the friction coefficient of the test fluid was measured in accordance with the conditions specified in Figure 4. Fluids showing a positive $\mu$-V curve which means that the friction coefficient increases with sliding speed would be able to prevent uncomfortable vibration which is called shudder phenomenon. Following the initial measurement of $\mu$-V characteristics, the durability test
TABle 1: Compositions of test oils.

\begin{tabular}{|c|c|c|c|}
\hline & Oil A & Oil B & Oil C \\
\hline Phosphorus additive & $\checkmark$ & $\checkmark$ & $\checkmark$ \\
\hline Calcium detergent & $\checkmark$ & $\checkmark$ & $\checkmark$ \\
\hline Dispersant & $\checkmark$ & $\checkmark$ & $\checkmark$ \\
\hline Friction modifier A & & $\checkmark$ & \\
\hline Friction modifier B & & & $\checkmark$ \\
\hline $\mathrm{Ca}$ (mass \%) & 0.06 & 0.06 & 0.06 \\
\hline $\mathrm{P}$ (mass \%) & 0.06 & 0.06 & 0.06 \\
\hline Viscosity $\left(\mathrm{mm}^{2} / \mathrm{s} 100^{\circ} \mathrm{C}\right)$ & 7.1 & 7.1 & 7.1 \\
\hline
\end{tabular}

was repeated under the conditions specified in Figure 4, and then the $\mu-\mathrm{V}$ performance measurement was carried out at 24-hour intervals.

2.4. Test Oils. Table 1 shows the composition of the test oils. The lubricants used were a hydrocracked mineral group III oil base blended to contain each additive. Phosphorus additive as an antiwear agent was added at the same concentration of 0.06 mass \% into all tested oils. Calcium detergent and boron dispersant are blended in all samples. These additives are normally used in CVTFs in order to keep the transmission clean and are also known to play an important role in controlling $\mu-\mathrm{V}$ characteristics for lockup clutch [14]. In order to explore effective friction modifiers (FMs), FM A (Nitrogen-type) and FM B (Ester-type) were added into Oil $\mathrm{B}$ and Oil C, respectively.

\section{Experimental Results}

3.1. Metal-Metal Friction Characteristics Tested by LFW-1. Figure 5 shows the metal-metal friction characteristics tested by LFW-1. The measurements were repeated three times for each sample, and the standard deviation of the measured data was within 0.002 . First, Oil A composed of phosphorus 


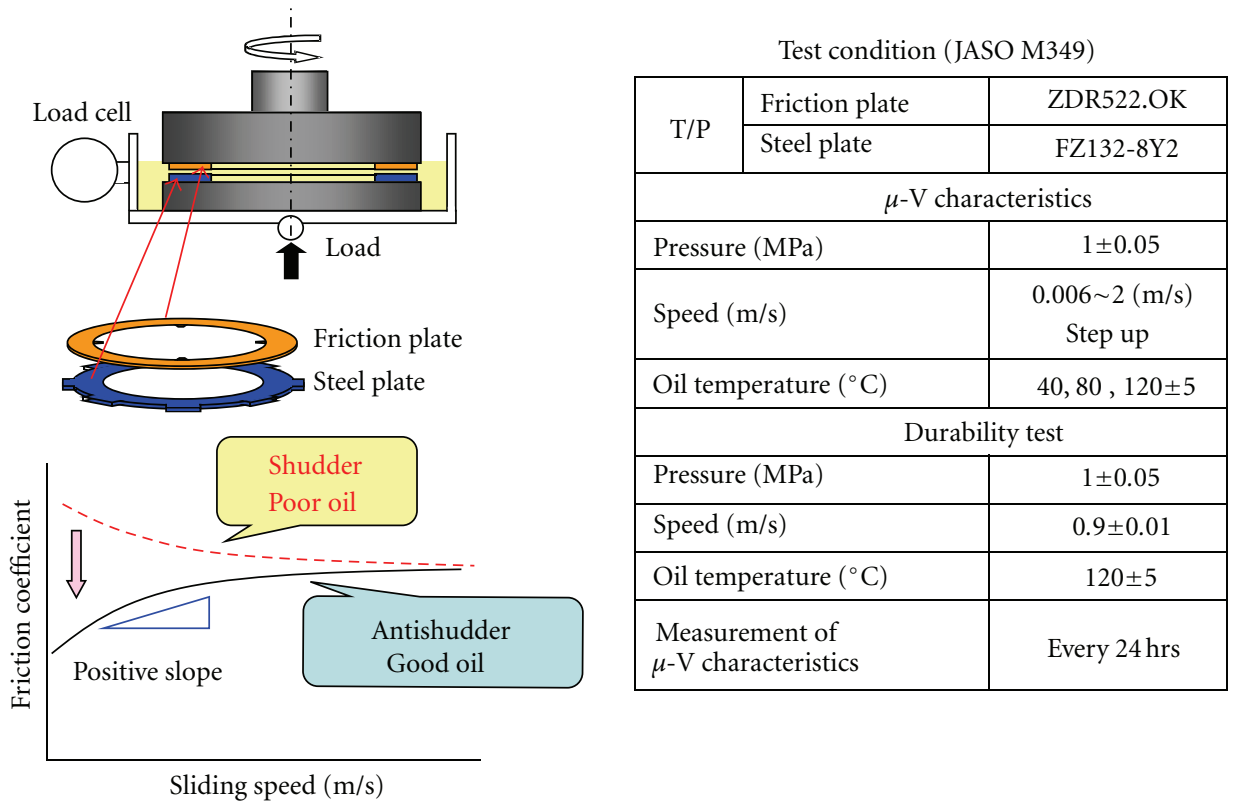

Figure 4: Schematic of Low Velocity Friction Apparatus (LVFA).

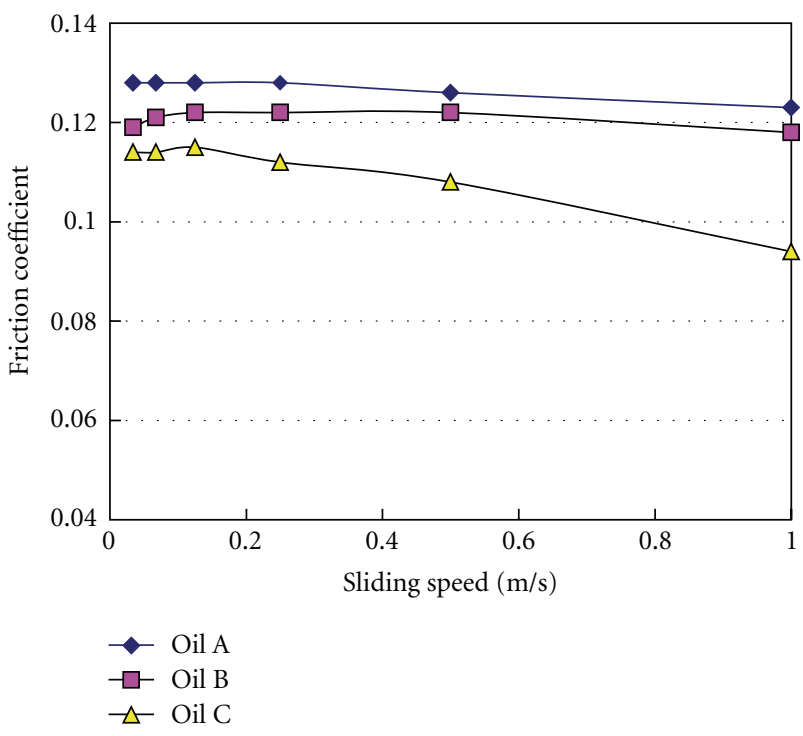

FIGURE 5: Metal-metal friction characteristic of test oils.

additive, calcium detergent, and dispersant shows the highest friction level of all tested oils. Oil B with FM A demonstrated the almost same friction level as Oil A. In the case of Oil C containing FM B, there was $24 \%$ decrease in friction coefficient at $1.0 \mathrm{~m} / \mathrm{s}$ compared with Oil A. FM B gives a great impact on decreasing the metal-metal friction coefficient.

3.2. Surface Analysis on the Posttest Block. X-ray photoelectron spectroscopy (Joel JPS-9010MC XPS) and AFM (Veeco Caliber AFM) were used to investigate the potential link between the friction characteristics and the morphology of tribofilms. Before surface analysis, the test specimens were washed by immersion in hexane in order to remove residual oil and wear debris. XPS analysis identifies the elements in a tribofilm to a depth of approximately $50 \mathrm{~nm}$ and analyzes their chemical bonding conditions by detecting the kinetic energy of discharged photoelectrons. In this study, an X-ray beam with photon energy of $\mathrm{Mg}-\mathrm{K} \alpha(10 \mathrm{kV})$ irradiated the centre of the test surface over a $1 \mathrm{~nm}$ diameter spot. After 15 s sputtering by argon irradiation, corresponding approximately to removal of a $5 \mathrm{~nm}$ thick layer from the surface, the XPS analysis was repeated to obtain information on the composition and changes in bonding conditions from the surface to the new depth.

Figure 6 shows XPS depth profile in the tribofilms on the test block from samples, Oil A, B, and C. Peaks corresponding to calcium carbonate $\left(\mathrm{CaCO}_{3}\right)$ and calcium phosphates $\left(\mathrm{CaHPO}_{4}\right.$ or $\left.\mathrm{Ca}_{2} \mathrm{P}_{2} \mathrm{O}_{7}\right)$ are at $347.3 \mathrm{eV}$ and $347.6 \mathrm{eV}$, respectively. In the case of Oil A, there is a sharp peak at $347 \mathrm{eV}$, as shown in Figure 6. The allowance error of the measurement was within $\pm 0.5 \mathrm{eV}$ in binding energy. Some calcium phosphates and calcium carbonate are likely to be generated on the rubbing surface. These calcium species were detected from the surface to more than $90 \mathrm{~nm}$ depth. The XPS profile with Oil B is quite similar to that of Oil A, which means that calcium species might be formed on the surface as well as Oil A. There is a peak at $347 \mathrm{eV}$ in the case of Oil C. However, the presence of calcium species was identified from the surface to at most $40 \mathrm{~nm}$ and therefore the thickness of the calcium compounds from Oil C was thinner than Oil A and B.

AFM allows a real surface investigation of tribofilm morphology at the nanometer scale [15]. In this study, AFM images were recorded in contact mode with a V-shaped $\mathrm{Si}_{3} \mathrm{~N}_{4}$ cantilever. To ensure consistency, the same probe was used for scanning each sample and the specified resolution in the normal direction $1 \mathrm{~nm}$. It is unlikely that the AFM tip would damage the surface because this contact force level 


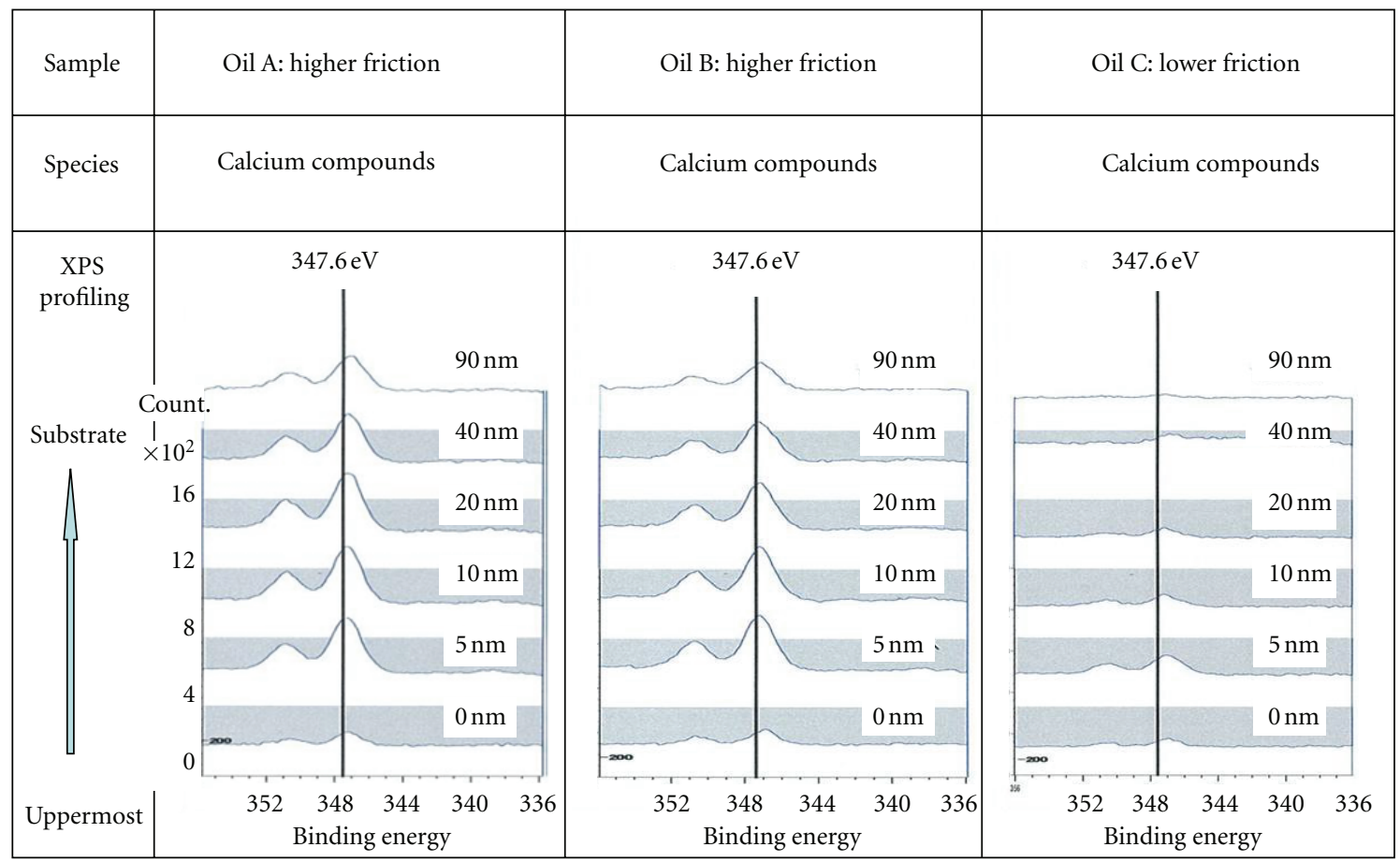

FIGURE 6: XPS spectra of tribofilm on the posttest block by LFW-1.

is extremely low compared with contacting force during the friction tests and the expected mechanical properties of the tribofilm.

Contact force mode AFM was used to characterize the nature of the tribofilm on the blocks. The central part of the wear track on the posttest block was scanned over $50 \mu \mathrm{m} \times 50 \mu \mathrm{m}$ at a rate of $200 \mu \mathrm{m} / \mathrm{s}$. Figure 7 illustrates the AFM topographic images of the posttest blocks derived from the tested oils. Note that the brighter parts in the AFM images represent the higher positions on the surface. Very interestingly, the posttest surface with Oil A exhibits a clearly dense deposition structure: the depositions having 1-5 $\mu \mathrm{m}$ elongated in the sliding direction. Furthermore, highly dense depositions can be observed on the wear scar from Oil B. These depositions might be composed of calcium carbonate and calcium phosphate from the XPS results as shown in Figure 6. However, the surface from Oil C does not possess distinct depositions. In addition, the ridges exist in the central part of wear track and the sides are polished, which might be due to the lack of the generation of calcium compound film on the surface. These results suggest that the frictional behavior strongly depends on the local morphology of the tribofilms derived from the lubricants' additives.

3.3. Transmittable Torque Capacity of Test Oils. Figure 8 shows the torque capacity of test oils, which were conducted varying the secondary pulley clamping force from 19.3 to $36.8 \mathrm{kN}$ at a constant primary pulley speed of $14 \mathrm{~m} / \mathrm{s}$ and a low speed ratio of 2.3. The torque capacity of Oil A at pulley force $36.8 \mathrm{~N}$ was normalized as a torque capacity of 1 . The torque capacity of tested oils increased in proportion with the pulley force, and the repeatability of measured values was within $\pm 3 \%$. The torque for Oil $\mathrm{A}$ was the greatest of all tested oils and $17 \%$ greater than that of Oil C. The torque for Oil B was almost same level as Oil A at higher load condition. The difference in the torque capacity of the test oils corresponds with the results by LFW-1, as shown in Figure 5, which justifies the use of LFW-1 tribometer as a test method for assessing torque capacity of B-CVT. It is vital for greater torque capacity to give higher boundary friction coefficient between the metal contacting interfaces.

Higher torque capacity fluids will bring out a potential for improving the transmission efficiency in the CVT units. Oil A gave $17 \%$ greater torque capacity than Oil C at $36.8 \mathrm{kN}$ pulley clamping force. When the secondary pulley force was reduced from 36.8 to $25 \mathrm{kN}$ (by $32 \%$ ) for Oil A, Oil A obtained the same torque capacity level as Oil $\mathrm{C}$ with a pulley force of $36.8 \mathrm{kN}$. Therefore, applying higher torque capacity fluid to CVT units could contribute to reduce the maximum required pulley clamping force. It would be possible to have lower oil pump load, which results in the reduction of total power loss in the CVT unit.

3.4. Antishudder Performance for Lockup Clutch. Figure 9 shows antishudder performance of test oils evaluated at $80^{\circ} \mathrm{C}$ by using LVFA. The friction coefficient Oil A is almost constant at a lower speed condition between 0.006 and $0.3 \mathrm{~m} / \mathrm{s}$, which implies a negative impact on antishudder property. Oil $\mathrm{B}$ and $\mathrm{C}$ with friction modifiers demonstrated a positive $\mu-\mathrm{V}$ curve at less than $0.3 \mathrm{~m} / \mathrm{s}$, thus excellent antishudder performance. Kugimiya [14] studied the effects of each typical additive applied to ATFs on $\mu-\mathrm{V}$ characteristics. Most of the friction modifiers (alcohol, amine, acid, and amide) reduce friction coefficients at lower sliding speeds. 


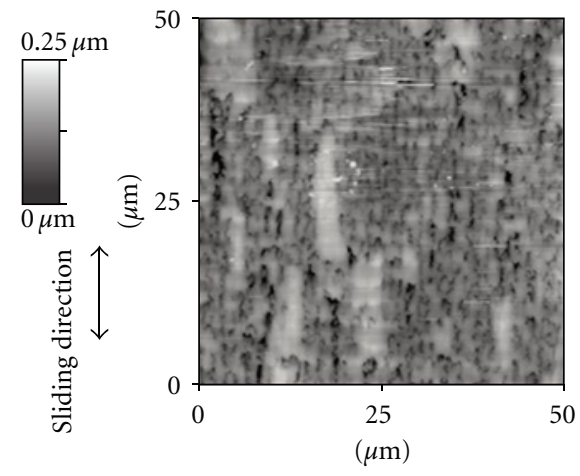

Oil A: higher friction

(a)

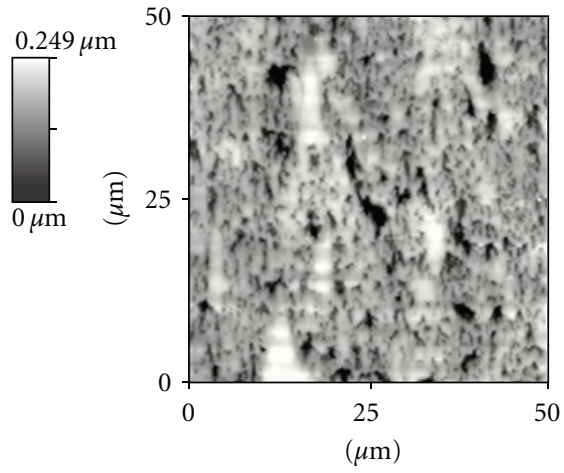

Oil B: higher friction

(b)

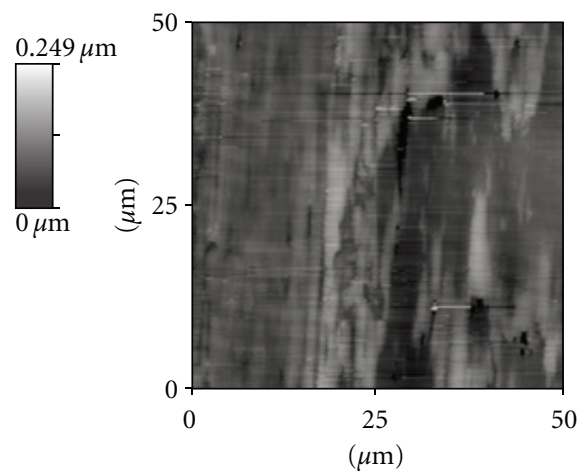

Oil C: lower friction

(c)

FIgURE 7: AFM image on the posttest block by LFW-1.

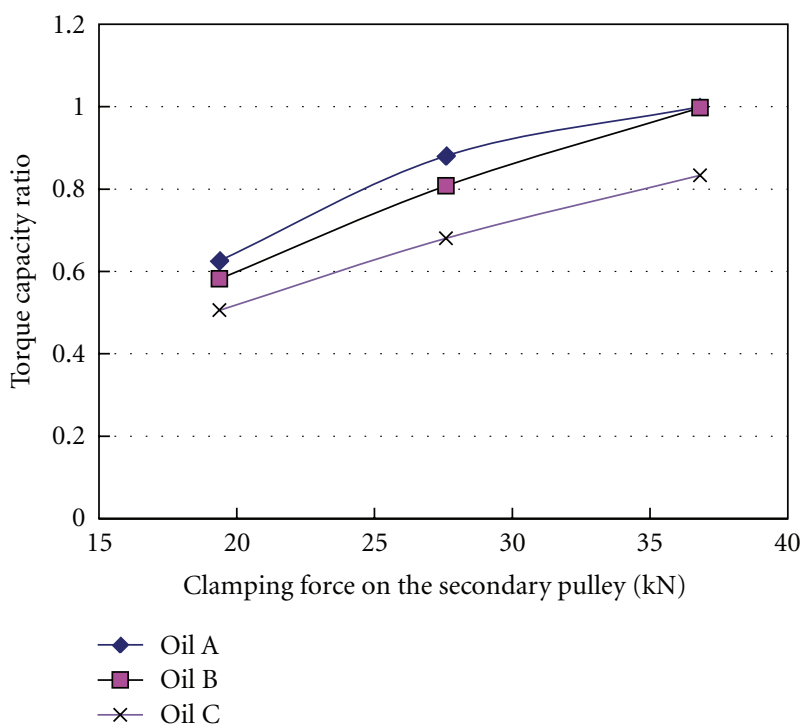

Figure 8: Transmittable torque capacity of test oils using belt CVT bench tester.

Dispersant and detergent can increase friction coefficients at higher sliding speed. From these effects, Oil B and C showed a positive $\mu$-V curve in the LVFA.
Next, the antishudder durability of test oils is shown in Figure 10. An approximate expression representing $\mu-\mathrm{V}$ characteristics at $40^{\circ} \mathrm{C}$ was obtained from the friction calculated by (3), and the reference for judgment of antishudder service life shall be $d \mu / d V(0.3)$ :

$$
\frac{d \mu}{d V(0.3)}=\frac{\left(\mu_{0.3}-\mu_{0.006}\right)}{(0.3-0.006)},
$$

where $\mu_{0.3}$ and $\mu_{0.006}$ are friction coefficients at sliding speed of 0.3 and $0.006 \mathrm{~m} / \mathrm{s}$, respectively.

In this study, antishudder service life was defined when the value of $d \mu / d V(0.3)$ reaches zero.

The result as shown in Figure 10 includes the antishudder life of JASO reference transmission fluid TIII evaluated by the same test apparatus, and the $d \mu / d V(0.3)$ for TIII was below zero at 168 hours durability. On the other hand, the $d \mu / d V(0.3)$ for Oil B still maintained a positive value at more than 240 hours, indicating longer antishudder service life than TIII.

In commercial use of CVT fluids, two different lubricants would not permit optimizing the performances according their respective purposes. This means that the CVT fluid must be compatible with the components in the whole CVT unit such as the belt and pulley, wet clutch, gears, and bearings. From these results, this additive formulation such as Oil 


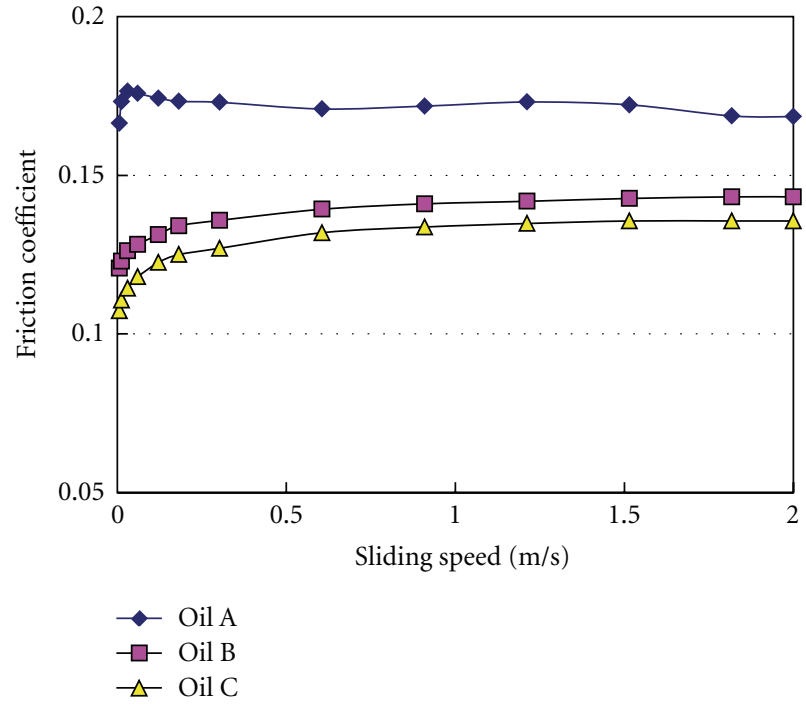

FIGURE 9: Antishudder performance of test oils by LVFA. (Oil temp. $80^{\circ} \mathrm{C}$, after running-in).

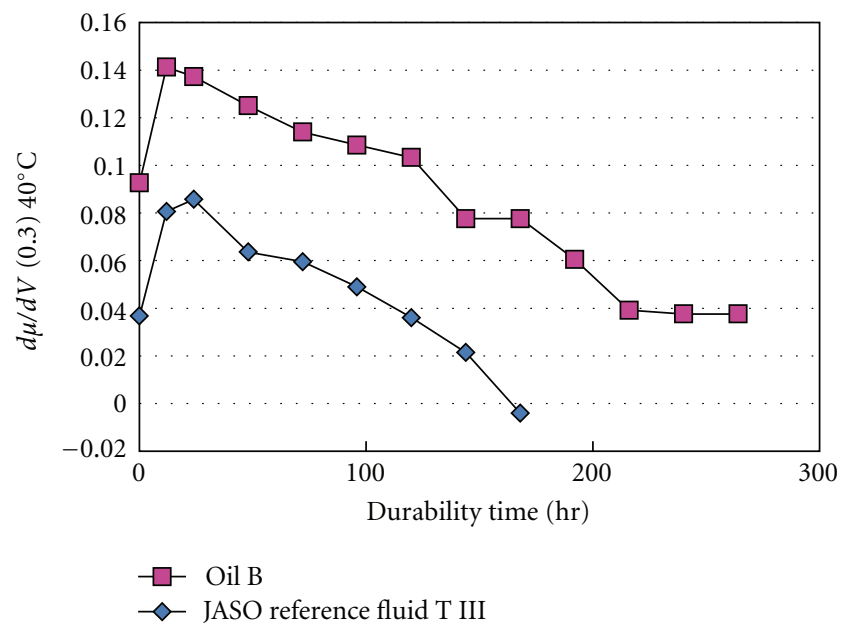

FIGURE 10: Antishudder durability of test oils.

B would attribute for improving antishudder performance keeping metal-metal friction coefficient.

\section{Discussion}

Oil B including phosphorus additive, calcium detergent, dispersant, and FM A showed a higher metal-metal friction coefficient and good antishudder performance. Here, the reason for the higher friction between the metals obtained by Oil B is discussed. From the results of XPS analysis as shown in Figure 6, much thicker calcium tribofilm species were identified on the wear scar with Oil B than the case of Oil C. The films derived from Oil B shown in Figure 7 therefore exhibit dense depositions in the sliding direction while the surface with Oil C was not uniform and the side parts were worn out. Taylor and Spikes [16] showed that the ZnDTP reaction film appears to inhibit lubricant entrainment into the contact, thereby leading to a reduced elastohydrodynamic lubrication (EHL) film thickness compared with ZnDTPfree lubricants. It is assumed that the thicker and dense tribofilm derived from Oil B plays a role preventing wear and inhibiting the entrainment of lubricant into the interface, resulting in higher friction.

Furthermore, the difference in the behaviors of tribofilm formation and friction characteristics between FM A in Oil $\mathrm{B}$ and FM B in Oil C in the LFW-1 and LVFA is discussed. Both FM A and B could play a role in decreasing friction coefficient under a lower speed around $0.06 \mathrm{~m} / \mathrm{s}$ and lower contacting pressure of $1 \mathrm{MPa}$ in the LVFA. However, FM A and $\mathrm{B}$ gave a different impact on the metal-metal friction at a higher pressure of $0.6 \mathrm{GPa}$ in the LFW-1. FM A in Oil B did not disturb the formation of calcium tribofilm species on the rubbing surface, as shown in Figure 7 AFM topography. FM B in Oil C might more strongly adsorb the surface leading to preventing from forming calcium tribofilm species, consequently with a lower friction. The different effects of FM A and B on the LFW-1 and LVFA test are likely to be influenced by tribological conditions such as contacting pressure and sliding speed between the two tests.

\section{Conclusions}

Belt CVT lubrication oils (B-CVTFs) must be able to produce a greater transmittable torque capacity between the belt and pulley and an excellent antishudder property for lockup clutch system in CVT units. The effect of lubricant additives was investigated for improving these performances of BCVTs. In addition, surface analysis techniques were utilized to gain a novel insight into the chemical composites and morphology of the tribofilms. The findings may be summarized as follows.

(1) The lubricant additive formulation composed of calcium detergent and phosphorus antiwear agent demonstrated a higher metal-metal friction coefficient, and the process of boundary lubricant film formation derived from these additives used in B-CVTFs strongly impacts on the tribological property.

(2) A sort of lubricant formulation is found to give an excellent antishudder performance for wet clutch with keeping higher friction coefficient between the metals, which would result in improving the performance of B-CVTs.

\section{References}

[1] Japan Automobile Dealers Association, Annual Report of the Number of New Cars Registered, 31st edition, 2008.

[2] H. Mitsui, "Trends and requirements of fluids for metal pushing belt type CVTs," Journal of the Japanese Society of Tribologists, vol. 45, no. 6, pp. 13-18, 2000.

[3] K. Narita and M. Priest, "Metal-metal friction characteristics and the transmission efficiency of a metal V-belt-type continuously variable transmission," Proceedings of the Institution of Mechanical Engineers, Part J, vol. 221, no. 1, pp. 11-26, 2007. 
[4] T. Ishikawa, Y. Murakami, R. Yauchibara, and A. Sano, "The effect of belt drive CVT fluid on the friction coefficient between metal components," SAE Paper 972921, 1997.

[5] H. Fujita and H. A. Spikes, "The formation of zinc dithiophosphate antiwear films," Proceedings of the Institution of Mechanical Engineers, Part J, vol. 218, no. 4, pp. 265-277, 2004.

[6] S. Bec, A. Tonck, J. M. Georges, R. C. Coy, J. C. Bell, and G. W. Roper, "Relationship between mechanical properties and structures of zinc dithiophosphate anti-wear films," Proceedings of the Royal Society A, vol. 455, no. 1992, pp. 41814203, 1999.

[7] Z. Yin, M. Kasrai, M. Fuller, G. M. Bancroft, K. Fyfe, and K. H. Tan, "Application of soft X-ray absorption spectroscopy in chemical characterization of antiwear films generated by ZDDP Part I: the effects of physical parameters," Wear, vol. 202, no. 2, pp. 172-191, 1997.

[8] J. M. Martin, C. Grossiord, T. L. Mogne, S. Bec, and A. Tonck, "The two-layer structure of Zndtp tribofilms, part I: AES, XPS and XANES analyses," Tribology International, vol. 34, no. 8, pp. 523-530, 2001.

[9] M. Muraki and A. Oshima, "Friction-velocity characteristics of oils containing zinc dialkyldithiophosphates and analysis of their tribofilms," Journal of Japanese Society of Tribologists, vol. 56, no. 8, pp. 523-529, 2011.

[10] JASO M358, "Standard test method for metal on metal friction characteristics of belt CVT fluids," 2005.

[11] J. D. Micklem, D. K. Longmore, and C. R. Burrows, "Modelling of the steel pushing V-belt continuously variable transmission," Proceedings of the Institution of Mechanical Engineers, Part C, vol. 208, no. 1, pp. 13-27, 1994.

[12] C. Morgan and R. Fewkes, "Development of a belt CVT fluid test performance using the VT20/25E," SAE Paper 2002-012819, 2002.

[13] JASO M349, "Road vehicles-test method for anti-shudder performance of automatic transmission fluids," 1998.

[14] T. Kugimiya, "Effects of additives for ATF on $\mu$-V characteristics," in Proceedings of International Tribology Conference, vol. 2, pp. 1355-1360, Nagasaki, Japan, 2000.

[15] A. J. Pidduck and G. C. Smith, "Scanning probe microscopy of automotive anti-wear films," Wear, vol. 212, no. 2, pp. 254264, 1997.

[16] L. J. Taylor and H. A. Spikes, "Friction-enhancing properties of ZDDP antiwear additive: part I-friction and morphology of ZDDP reaction films," Tribology Transactions, vol. 46, no. 3, pp. 303-309, 2003. 

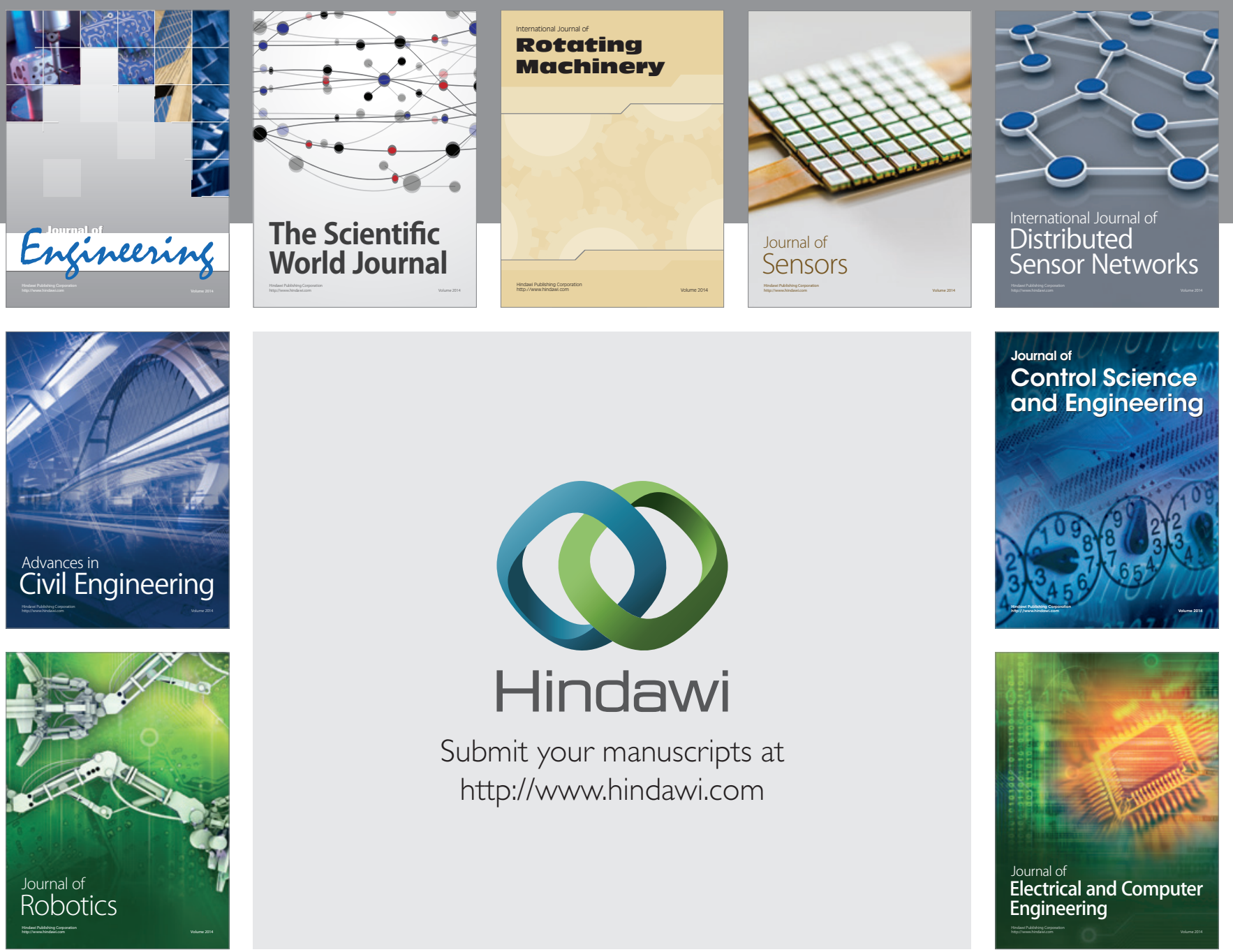

Submit your manuscripts at

http://www.hindawi.com
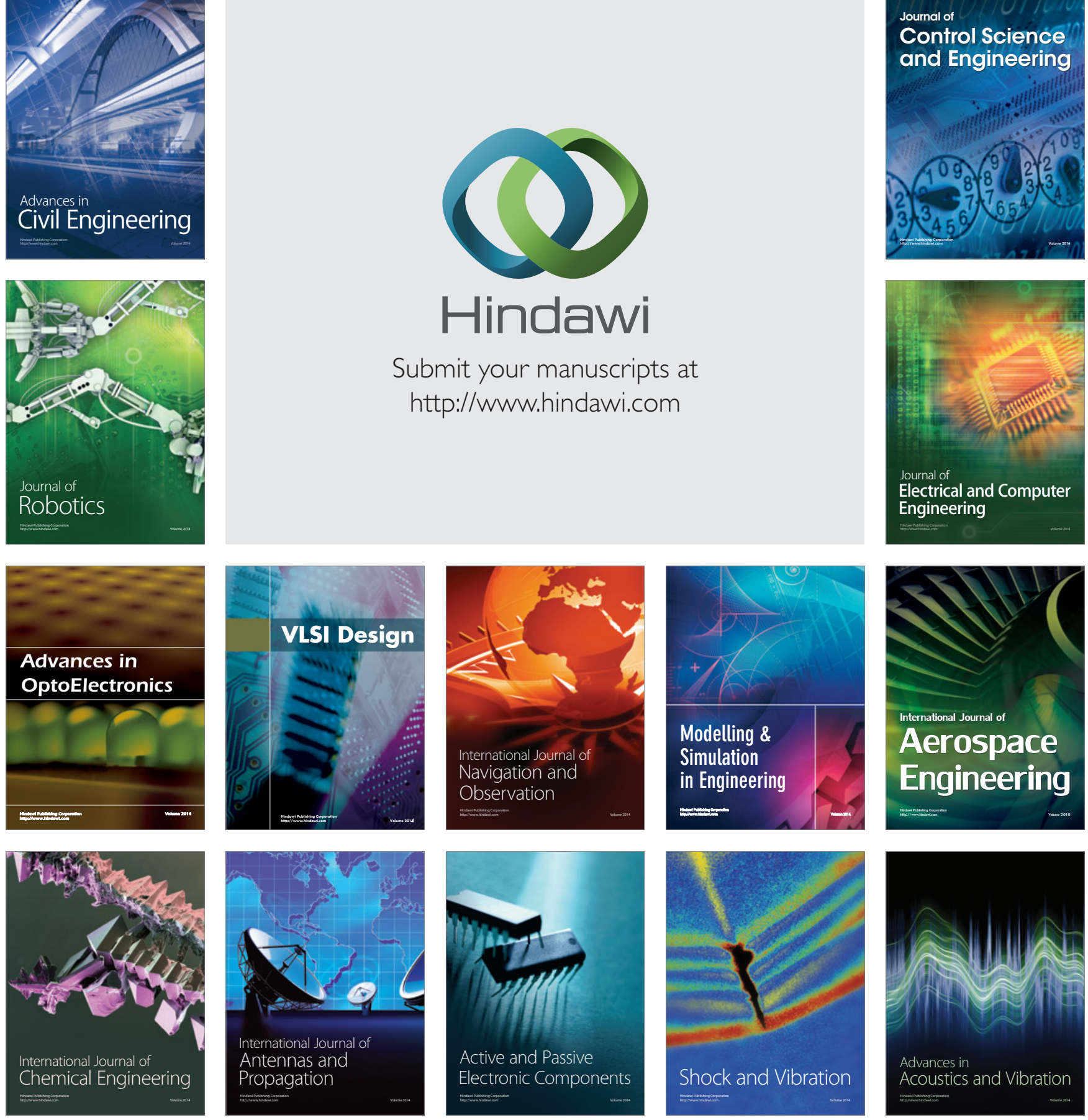